\title{
«ПРЕСТУПЛЕНИЕ И НАКАЗАНИЕ» ФЕДОРА ДОСТОЕВСКОГО ПО ВЕРСИИ ГАСТОНА БАТИ
}

\begin{abstract}
Аннотация
В статье повествуется о театральной адаптаиии романа Федора Достоевского Преступление и наказание. Спектакль был впервые предложен публике режиссёром Гастоном Бати в 1933 году на сцене театра Монпарнас. Постановка имела огромный успех и вошла в золотой запас истории франиузского театра. Многие годы Преступление и наказание по версии, предложенной Гастоном Бати, идёт на сценах франиузских театров. В статье впервые вводится в оборот новый архивный документ.

Ключевые слова

Федор Достоевский, Преступление и наказание, Гастон Бати, франиузский театр, театральная адаптация, Картель четьрёх
\end{abstract}

О Гастоне Батиㄹ пишут, как о фигуре, сыгравшей особую роль в театральной жизни Франции первой трети XX-го столетия. С ним связывают значительное влияние на «идейно-театральные поиски эпохи» (Гительман 1988: 37). Он был одним из лидеров «Картели четырёх» ${ }^{3}$ (совместно с Шарлем Дюлленом, ${ }^{4}$ Луи Жуве, ${ }^{5}$ Жоржем Питоевым ${ }^{6}$. Об

1 nadinor@mail.ru

2 Гастон Бати (фр. Gaston Baty; 1885-1952) - французский драматург и режиссёр, теоретик театра, один из основателей в 1927 году театра «Картель» (фр. Cartel des quatre).

3 См. например: (Финкельштейн 1974; Borgal 1963; Hort 1976).

4 Шарль Дюллен (фр. Charles Dullin;1885-1949) - французский актёр и театральный режиссёр. В составе труппы «Театра искусств» в 1911 году он сыграл свою первую значительную роль - Смердякова в инсценировке «Братьев Карамазовых», сделанной Жаком Копо и Жаном Круэ, которую поставил режиссёр Андре Дюрек.

5 Луи Жуве (фр. Jules Eugène Louis Jouvet, 1887-1951) - французский режиссёр, актёр театра и кино.

6 Георгий Питоев, или Жорж Питоев (фр. урождённый Питоян Геворг Ованесович, Georges Pitoëff; 1885-1939) - русский и французский актёр и театральный режиссёр, армянин по 
истории его жизни и театральной биографии написано немало. Это был разносторонне и высокообразованный человек, с юности твердо поверивший в свое служение театру. Его университеты, это литературный факультет Лионского университета, лекции по истории искусства в Мюнхенском университете, а в некоторых источниках можно найти упоминание и на поездку в Россию в 1907-1908 годы для изучения системы Станиславского.

Собственно профессиональные маршруты на его театральном поприще начинаются с 1919 г., когда с ним подписывает контракт Фирмен Жемье. ${ }^{7}$ А в 1921 г. он затевает собственный театральный проект - «Compagnons de la Chimère» - объединивший различных молодых авторов. В 1923 г. строится специальное здание - барак. Отсюда и название - La Baraque de la Chimère (Барак Химеры). В манифесте, опубликованном в связи с открытием нового театра, было сказано: "Химера, которую мы избрали эмблемой... - это женщина-птица из северных сказок, могучие крылья уносят ее в небо, но у неё есть когти, которые крепко держатся за почву... Если хотите, это символ искусства, жаждущего универсальности и равновесия, стремящегося к гармонии, вплоть до примирения сил, которые вековая привычка искусственно противопоставляла друг другу, - духа и материи, сверхъестественного и естественного, человека и вещи” (цит. по Гительман 2012). Впрочем, история «Барака» завершилась спустя несколько месяцев из-за финансовых проблем, и Бати вместе с труппой перебрался в Студию Елисейских полей. А с 1930 года он возглавил театр Montparnasse.

К этому времени у него уже были сформулированы собственные эстетические принципы, на которых он намеревался строить свой театр. Этому посвящены его программные работы: Театральные храмы (Les Cathédrales Dramatiques) (Baty 1919), Драма, требуюшяая реборм (Le Drame prétend réformé) (Baty 1920), Его величество слово (Sire le Mot) (Baty 1921), Le masque et l'encensoir: Introd. à une esthétique du théâtre (Baty 1926).

Гастон Бати упрекал французский традиционный театр в увлечении натуралистическим отражением «жизнеподобия», а кроме того, в зависимости от литературы. Для Бати смысл театра в «точном переводе

происхождению.

7 Фирмен Жемье (фр. Firmin Gémier; 1869-1933) - французский актёр, театральный режиссёр и театральный деятель, создатель Национального народного театра в Париже. 
чувства и мысли на язык жеста, декорации, слова» (Baty 1921: 8). Этому принципу режиссёр был верен всю свою театральную жизнь.

И, кроме того, уже в ранних постановках, на всех площадках, режиссер стремится добраться до религиозно-философских смыслов бытия человека, до его трагических метаний между добром и злом, между миром земных страданий и гармонией небесной высоты. С триумфальным успехом это прозвучало в спектакле «Преступление и наказание», предложенном парижской публике 21 марта 1933 г. на сцене театра Montparnasse.

Здесь уместно сделать небольшую историческую справку о начале театральной судьбы романа на французской сцене. ${ }^{8}$ Имя Достоевского впервые появилось на театральных афишах Франции в сезон 1888/1889 года. И именно с премьеры спектакля «Преступление и наказание», которым театр «Odeon» 15 сентября1888 года открывал сезон. Считается, что эта «встреча» состоялась в «переломную для развития сценического искусства Франции» пору (Гительман 1978: 55). Спектакль был решён в традициях «хорошо сделанной пьесы», однако она скорее тяготел к мелодраматическим конфликтам, ведя по которым героев Достоевского, создатели спектакля стремились обосновать именно поступок Раскольникова. И обосновать не столько в контексте драматических исканий нравственных координат героя, сколько в плоскости его переживаний за судьбу Сони, что и сводил в известной мере сюжет к криминальной интриге. За это упрекали спектакль, хотя и признавали за ним положительным итогом то общее послевкусие и у зрителей, и у критиков это вот она - «загадочная русская душа»... И этим, и именем писателя спектакль привлек внимание критиков и зрителей, но его не спешили заносить в список успешных открытий на театре.

Известный критик того времени Жюль Леметр 9 написал о постановке как о пьесе, тяготеющей к мелодраматизму, замешанному на специфически «славянском содержании» романа. "Crime et Chatiment n'est pas seulement un roman judiciaire; c'est, avant tout, une histoire d'âme" (Lemaître 1888-1898: 249). В нем действуют совестливые и гордые герои, способные к самопожертвованию не по совсем понятным французскому зри-

8 Более развёрнутый анализ см.: (Орлова 2017).

9 Франсуа Эли Жюль Леметр (фр. François Élie Jules Lemaître; 1853-1914) - французский литературный критик, глава «импрессионистской школы», новеллист и драматург, член Французской академии. 
телю мотивам. Почти гениальный Раскольников становится убийцей во имя спасения Сони Мармеладовой от необходимости продавать себя. "Rodion est fort intelligent; ses amis lui reconnassent presqe du genie. Il sent une puissance qui serait bienfaisante et qui ferait honneur à l'humanite si elle pouvait se deployer» (Lemaitre 1888-1898: 250).

Французской публике предложили сострадать падшим героям трущоб, что было для того времени элементом «нового театра». Так что с одной стороны, критики о постановке говорили как о неудачной, с другой ее оправдывал свежий ветер театральных поисков нового времени. В любом случае, роман «Преступление и наказание» хорошо воплощал для французского читателя отношение к Достоевскому как к писателю-проповеднику, религиозно-философские искания которого переживали все его герои. Они страдали, решая для себя мучительный вопрос нравственного выбора, совершали преступления и наказывали себя муками совести. Пусть не идеальная, но постановка 1888 г. на сцене театра «Odeon» навсегда вписана в анналы французского театра как первая трактовка великого романа Достоевского.

Можно считать, что первое успешное приближение к театральному воплощению на французской сцене замысла писателя состоялось именно в постановке Гастона Бати 1933 года. Об этих 1930-х говорят как о времени, когда Европа определяла себя в координатах наступающего фашизма. И критики немедленно связали концепцию Бати с этим драматическим фоном. Спектакль обращался к зрителю с предельно нравственными вопросами о «грехе и благодати», о «преступлении и наказании». Фигуры Сони Мармеладовой и Родиона Раскольникова понимаются как ключевые. В их поиски выхода из нравственных тупиков вовлекаются все персонажи. Соня трактуется не как жертва, не как та, которая искупает грех преступления Раскольникова. В ней закодированы символы спасающей женщины-матери. О сцене в комнате Сони Мармеладовой критики говорили, как о сцене Марии и Христа, Матери и Сына. Вот ее описание: в окне проступают очертания церкви, Раскольников склонился перед Соней в отчаянном бессилии, Соня простирает над ними руки, как бы закрывая его от беды, и благословляя. Мизансцена строится практически по канонам иконической живописи (Baty 1933).

Соня подчиняет себя задаче спасения Раскольникова, переживающего мучительный духовный кризис. Ее силы тоже на пределе истощения. В 
финальной сцене на кладбище спасающая ипостась Сони выражена в пределе. Кладбище. Вечереет. На переднем плане могильный холмик. Скамейка, на которой сидит поникшая Соня Мармеладова. Она как бы уже не способна бороться ни за себя, ни за кого бы то ни было. Но вот появляется Раскольников. Они медленно приближаются друг к другу. Раскольников падает, рыдая, перед ней на колени. И Соня не просто находит в себе силы, она уже излучает энергию веры в человека, в спасение его из бездн зла. Ее лицо лучится счастьем этого обретения. Она также падает на колени и стремится обнять Раскольникова, прижать к себе. И в этой их встрече на коленях - торжество добра и милосердия (Baty 1933: 17).

Ни один критик не обошел своим «потрясенным» вниманием сцену лестницы, по которой Раскольников поднимался для убийства: две площадки, одна над другой; лестница, соединяющая их и уходящая вверх и вниз; по две двери на каждой площадке. На заднем плане косые лучи заходящего солнца, пробивающиеся сквозь тусклые стекла, звук часов где-то за стеной... Все это уже готовило зрителя к чему-то леденяще ужасному. Раскольников медленно поднимался, судорожно сжимая перила, и проговаривая рассудочно, монотонно и убеждённо свою идею вседозволенности. Раскольников отсчитывает ступени: Quarante-six marches. Encore quatorz. C'est le compte. Donc je suis bien lucide. (8 heures sonnent) 8heures. Exactement comme je l'avais prévu. (Il arrive au palier supérieur.) Soixante. Voilà. Je nai rien oublié. Et mon pouls bat comme si de rien n'âtait! (Baty 1933: 6). Как описывают критики, атмосфера леденящего ужаса в зале достигала такого накала, что звук дверного звонка воспринимался как удар грома.

В одиннадцатой сцене, когда Раскольников уже после болезненного беспамятства, после прихода к нему Порфирия Петровича, зритель вновь будет вовлечен в это монотонное восхождение убийцы по лестнице, где он как бы тестирует себя на способность перешагнуть через преступление, убедить себя, что остался прежним. И вновь вечерние лучи сквозь тусклые стекла, и дрожащая рука судорожно сжимает перила, и где-то звуки шарманки, и его счёт ступеней: Quarante-six marches. Encore quatorze. Je comptais comme cela. Le logement où travaillaient les peintres est occupé maintenant. Soixante. J'ai tâté la hache sous mon paletot. Ce jour-là je navais pas la fièvre et jai sonné. (Il sonne.) Voilà bien le son fêlé que jentends depuis. Ainsi. Ainsi (Baty 1933: 18). И Раскольников звонит... Дверь распахивает работающий в квартире маляр. Совпадение нарушено. Рас- 
кольников раздавлен, потерян... Сверхчеловек раздавлен, уничтожена его идея...

Много лет спустя один из ведущих критиков написал об этих сценах: «Мы никогда не забудем Раскольникова, крадущегося по лестнице к своей жертве...» (Kemp R. 1956: 325).

В фигуре Порфирия Петровича прочитывался синоним официальной государственной власти, задача которой - держать человека в строгой дисциплине, тем самым защищая от него и общество, и его самого. Визуально это подчеркивалось военной униформой полковника. Вкрадчивая, мягкая тональность ведения беседы, неспешная и размеренная пластика движений, все говорило о непоколебимой уверенности этого персонажа в своей правоте: человек порочен по своей природе и только власть способна удержать его в границах законов общежития.

Бати опровергает эту правоту. В фигуре Раскольникова - путь/эволюция человека от порочной уверенности в своей вседозволенности до катарсиса нравственного осмысления бездн зла в себе и торжество покаяния. Побеждает правота Сони. Финкельштейн об этом напишет так: «Бати не упустил ни одной возможности, чтобы показать, как все больше и больше проникается Раскольников Сониной правдой. Отступая от романа, он вел Раскольникова не в полицию, а к публичному покаянию» (Финкельштейн 1974: 254).

В двадцатой, заключительной картине мы видим, как Раскольников вместе с Соней спускаются по крутой узкой улочке, дома которой теснились и уходили вверх в почти не проступающее вечернее небо. Это те самые петербургские сумеречные дворы-колодцы. И все также уныло наигрывает шарманка. И две фигуры двигаются между безучастно стоящими по сторонам другими персонажами пьесы. Вот они приближаются к авансцене. Раскольников падает на колени лицом к публике и произносит заключительные слова пьесы: C'est moi qui ai tué, à coups de hache, Aliona Ivanovna, pour la voler. Занавес!!! (Baty 1933: 30).

Гастон Бати верен себе. В сценах спектакля все подчинено его базовому принципу: смысл театра, это «точный перевод чувства и мысли на язык жеста, декорации, звука, слова одновременно» (Cahiers Gaston Baty 1966: 31). Он все это идеально подгоняет под ту идею, которую, - он в этом убеждён абсолютно - провидел у Достоевского. 
Атмосферы «русского колорита» Бати добивался через «русскую душевность», для чего даже отменил свое правило не привлекать актеров со стороны. На роль матери Раскольникова была приглашена бывшая актриса Московского Художественного театра Мария Германова. ${ }^{10}$ Считается, что партнёрство с актрисой такой душевной силы помогло воссоздать драму покаянного сына, который обращается к матери со словами мольбы о любви: «Petite maman, quoi qu’il arrive, quoi que vous, entendiez dire de moi, maimerez-vous toujours comme à present?... J'ai peur, maman, maman! (Baty 1933: 26).

Думается, что и русская художница по костюмам Шуманская Ольга

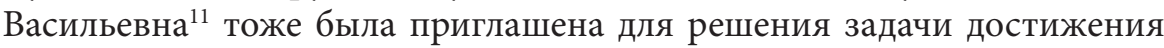
достоверного русского колорита, далёкого от расхожего псевдостиля с «матрёшками/балалайками».

Сами декорации к спектаклю создавались по эскизам Гастона Бати. Лишенные красочности, они были предельно просты, казались почти примитивными, без намека на декоративный эффект. А вместе с тем критики подчеркивали их тщательную продуманность до мельчайших деталей и линий и символическую выразительность. Декорации располагались по двум планам: переднему и заднему. На авансцену выносились конкретные места действия: комната Раскольникова, трактир, квартира старухи-процентщицы, скамейка и т. д. В глубине пространство насыщалось деталями, которые должны были подчеркнуть общую идею сцены. Например, в покаянной сцене на кладбище - могильный холмик и скамейка на переднем плане; здесь произойдет само событие покаяния. В глубине сцены в кровавом свете доминирует огромный крест, как бы символизируя религиозную глубину смыслов происходящего. Бати призывает зрителя пережить вместе с героями тревогу об ответственности за то, что происходит в мире и с людьми. Разворачивая перед зрителем «преступление, которое преследует самое себя», Бати ведет своих героев от картины к картине, прослеживая мельчайшие психологические повороты их переживаний.

10 Германова Мария Николаевна (наст. фам. Красовская-Калитинская; 1884-1940) русская актриса, режиссёр, педагог, эмигрировавшая из России в 1922 году. Известна ее роль в фильме с участием актёров МХТ «Раскольников» по роману Ф. Достоевского «Преступление и наказание», был снят в 1923 году Робертом Вине (Германия).

11 Шуманская Ольга Васильевна (в замужестве де Курвиль; 1896-1971) - художница театра и кино. Около 500 макетов декораций и костюмов, выполненных О. Шуманской, были переданы ею в 1948 году в дар Bibliothèque nationale de France. Département des arts du spectacle. См.: Cote: COL-133 Fonds Olga Choumansky (1896-1971) [ca 1920-1970]. 
Как известно, спектакль имел колоссальный успех, почти полтора года билеты на него расходились практически мгновенно. Спектакль имел и большой гастрольный успех в Швейцарии, Голландии, Норвегии, Венгрии, Финляндии, Ирландии, Швеции, Италии, Южной Америке. В репертуаре театра «Монпарнас» спектакль сохранился вплоть до начала Второй мировой войны. Показанный в концертном варианте уже в оккупированном Париже, он был запрещён немецкими властями (см. Гительман 2012: 34-63).

В 1945 г. на волне пиетета к русским - победителям в той страшной войне, французские театры особенно активно инсценируют произведения русской классики. И конечно, яркая, глубоко нравственная постановка Бати особенно уместна. Тем более, что как известно, маэстро так тщательно и детально прописал сценарий и декорации, что это обеспечило, судя по архивам, довольную долгую сценическую судьбу этой версии. И судя по всему, Гастон Бати щедро предоставлял такую возможность. Сценарий образца 1933 года был практически сразу запущен в широкую печать. ${ }^{12}$ В архиве библиотеки Арсенал в фонде Бати ${ }^{13}$ хранятся множество его черновиков, которые не только отражают стиль работы режиссера над постановкой, но позволяют возможно точно реконструировать спектакль.

19-22 апреля 1945 года на сцене Колледжа St.-Joseph ${ }^{14}$ в Пуатье играли спектакль «Преступление и наказание» именно по версии Гастона Бати. Спектакль, как следует из программки, предварялся пением Марсельезы и минутой молчания в память о всех погибших в войне. Также должны были исполняться произведения русских композиторов Чайковского, Римского-Корсакова и Рахманинова. Кроме того, программа информирует, что Гастон Бати консультировал постановщиков. Nous tenons à dire ici notre reconnaissance à Monsieur Gaston Baty et à son regisseur de scene, Monsieur Gil Colas, pour l'accueil bienveillant qu'ils nous ont reserve et pour les précieux conseils qu'ils ont bien voulu nous donner.

Именно об этом спектакле пишет свои впечатления автор письма, которое в архиве атрибутируется как «Письмо известного преподавателя

12 К слову сказать, есть эта версия и в Российской национальной библиотеке.

13 Bibliothèque nationale de France. Département des arts du spectacle. Fonds Gaston Baty (1885-1952). Cote: COL-285. Ancienne cote: COL-255. 1886-1973.

14 Lancien collège Saint-Joseph de Poitiers (lycée des Feuillants) devient cité judiciaire. 
русской литературы в Коллегиуме Руссикум, ${ }^{15}$ поверенного и близкого друга Вячеслава Иванова». ${ }^{16}$ Документ хранится в архиве библиотеки Ришелье. Письмо подписано именем А. Паппадатто. К слову сказать, ни в одном из известных архивов, посвящённых Вячеславу Иванову, такой персоны мне найти не удалось. Однако мои поиски привели к тому, что, с известной долей уверенности можно указать имя автора. Это Альфред Львович Паппадатто (Pappadato Alfred; 1879-1957), уроженец Одессы, где был директором гимназии. Из письма понятно, что его автор большую часть жизни прожил в России, эмигрировал после революции 1917 года. Хорошо знаком с русской литературой и философией. Не только понимает творчество Достоевского, но также хорошо знает о том, какое место занимает Достоевский в русской и западной философии. Таким образом, философия Достоевского это есть общая тема и для автора письма, и для Вячеслава Иванова, известного своими работами о Достоевском. Сопоставимы и время возможных пересечений двух коллег. Как известно, Вяч. Иванов с 1936 года преподавал в Коллегиум Руссикум. Автор письма также был преподавателем этой коллегии. Очевидно, что в жизни этих двух персон имеют место ряд важных пересечений: общая родина - Российская империя; эмиграция и жизнь в Италии в 1930-1940-е годы; преподавание русской литературы в Коллегиум Руссикум в этот период. Уверена, что открытие данного письма не только вводит в оборот неизвестный архивный документ, но и новое имя из окружения Вячеслава Иванова. Судя по тексту, автор письма обращается к духовному лицу (епископу), под патронажем которого, по-видимому, была реализована постановка спектакля. Уместно процитировать письмо, разумеется, не целиком.

\section{Мой Преподобный и дорогой отеи,, ${ }^{17}$}

Я очень глубоко впечатлен пьесой, которую только что разыграли ваши актеры. Хочу вам сказать, никогда я не предполагал, что какой-нибудь молодой человек может в настоящее время так полно проникнуться светом Достоевского. Его христианство, как мне кажется, далеко от идей, которые сегодня предлагают западники ... Для западных людей эти религиозные представления Достоевского всегда могут показаться неожиданными и оригинальны-

15 лат. Pontificium Collegium Russicum.

16 Bibliothèque nationale de France. Département des arts du spectacle. Fonds Gaston Baty (1885-1952). Cote: COL-285. Ancienne cote: COL-255. 1886-1973.

17 Перевод выполнен мною - Н.О. 
ми, но для тех, кто немного знаком с трудами греческих отцуов и древнерусской литературой, все они кажутся естественными и нормальнылми [...]

Разумеется, ваши актеры вообще не могли осознать полностью идеи Достоевского, не могли «объяснить» ее из своих, религиозных, умозаключений [...] Но они сделали лучше, они получили - благодаря пьесе, от господина Бати - то внутреннее погружение, которое позволило им по-настоящему реализовать идеи, страдания, искания героев Достоевского. И они преуспели в этом больше тайной интуицией своего глубокого $Я$ [...] ибо “дитя обладает удивительным даром провидения [...]” А в драматическом искусстве провидение куда важнее интеллекта [...]

Я не буду рассказывать вам обо всех актерах. Вот некоторые мысли о некоторых из них.

Раскольников - Франсуа Клод Оури - уловил мучения, страдания, которые мучают человека, захваченного идеей. [...] Слишком долгое страдание вызывает [...] этот бунт истощуает, уничтожает и приводит к покорности воле Божьей, покорность, которую символизирует Соня [...]

Франсуа Мулен - Соня. Где она могла найти этот тон спокойного, глубокого смирения, этот покой подчинения воле Божьей? Где она могла найти такие чистые и искренние акцентыл? A потом эта спокойная уверенность, эта твердость, с которой она диктует Раскольникову, что ему делать. Где она могла найти этот всегда одинаково печальный взгляд, эту манеру говорить, никогда не повышиая голоса, - и этот нерешительный жест правой руки, поднесенной к виску и не дающей результата? Я задал ей эти вопросы. Она была удивлена им и после раздумий призналась мне, что не знает.

Точно так же Николай - ученик Эрнеста Боло - как ему удалось зачать тот полный крах в душе молодого мужчины, который давно мечтал страдать за других (ибо грех каждого из нас есть грех всех) [...] Я никогда не забуду этот крик, тон его голоса, этот жест окончательного отчаяния, когда он падает на колени, чтобы обвинить себя в преступлении Раскольникова ... какое рвение в 
этой человеческой душе, и какое освобождение от ее изначальной, космической жажды страданий [...]

Если бы Франсуа-Ксавье Лаланн много лет бывал в русских трактирах, я мог бы понять, как он сумел создать роль Мармеладова... но ему ещзе нет восемнадцати. Он никогда не видел русских трактиров [...] но он был так похож, так типичен. Я могу сказать это, потому что я видел русские трактиры [...] а мне 66 лет, из них 40 я провел в России, [...] Очень верен капризный, созерцательный тон пьяного человека - его душераздираюший акцент - он, который знает, что он сходит с ума и чувствует, что в этом неразумии он ближе к истине, чем люди, которые не пьяны.

Порфирий - Мистер Раймонд ДОРДЕТ - хороший, отличный, великий актер, живущий свою роль с удивительной правдой, человек, очень нюансный, очень разнообразный... дикция и голос редки даже у профессиональных актеров. Но зачем ему военная форма? - У Достоевского Порфирий, пожалуй, загадочнее и трагичнее. Он больше страдает, и мы не знаем, чего он хочет; нам даже кажется, что он сам этого не знает.

Разумихин - Франсуа Мори - очень хорошо показал столь распространенный в России тип доброго товарища. Русское товарищество гораздо глубже, прочнее, сердечнее, чем на Западе. [...] Ha сиене он был самим собой, он преуспел в совершенстве.

В заключение хочу сказать еще два слова. [...] Из всех авторов современности мало кто сумел, как Достоевский, вывести из бездн нашего глубочайшего “я” могучие образы “я” и тревожные идеи, накопившиеся в них на протяжении столетий нашей христианской жизни...

Заслуга Гастона Бати состояла в том, чтобы выбрать и упорядочить диалоги Достоевского, не передельвая «для сцены» роман. Он тоже обладает высшим даром художественного провидения, который так редок и иенен. Ибо если бы не оно, вряд ли он мог преуспеть в этой потрясающей работе.

Благодаря адресата за приглашение, автор письма подчёркивает, что благодарность эта за «возможность прожить так интенсивно одновре- 
менно с великими идеями и великими чувствами Достоевского и простыми стремлениями человека».

Вне всякого сомнения, в основе успеха спектакля лежало гениальное проникновение Гастоном Бати в философию Федора Достоевского. Французский театр благодарно возвращается вновь и вновь к этой версии. В пользу популярности театральной адаптации Гастона Бати можно указать на постановки разных лет, например: 19 ноября 1971 в Théâtre populaire de Reims-Compagnie состоялась премьера Crime et châtiment / mise en scène de Robert Hossein; pièce en 20 tableaux de Gaston Baty; d’après l'oeuvre de Fédor Michaïlovitch Dostoïevski. Из статьи, опубликованной в la Lettre n 192 (26 novembre 2001) мы узнаем, что в Théâtre Marigny играли Crime et châtiment de Dostoïevski. Adaptation scénique Gaston Baty. Mise en scène Robert Hossein avec 33 comédiens. В отзыве говорится: "Un spectacle inoubliable, fidèle à l'esprit de l'auteur et à lépoque, qui démontre une fois encore les qualités éclectiques de metteur en scène et de directeur d'acteurs de Robert Hossein». C 12/06/2008 по 15/06/2008 в Salle des fêtes de Saint-Louis версия Crime et châtiment D’après Fedor Mikhaillovitch Dostoïevski, adaptation Gaston Baty, par les Malades d'Imaginaire, предложена режиссером Laya Ullrich. В аннотации к спектаклю читаем: Raskolnikov, jeune étudiant tue une vieille usurière. Brisé par ce meurtre, il rencontre Sonia, une prostituée à qui il confie son crime. Dostoïevski utilise cette relation comme une allégorie de l'amour de Dieu pour l'humanité déchue et du pouvoir de rédemption de l'amour. B 2016 в афише COMEDIA THEATRE присутствует Crime et Châtiment d'après Dostoïevski Adaptation de Gaston Baty. Mise en scène et création lumière Sophie Bélissent. Список этот может быть продолжен и продолжен.

В завершение статьи вернусь к словам из той самой первой программки 1933 года. В них манифест о том, что главный смысл работы над спектаклем был не в том, чтобы создать «хорошо сделанное и ловко подогнанное под вкус публики зрелище». Nous n'avons eu qu'une ambition: rester le plus près possible de notre modèle, respecter sa pensée toujours et souvent son texte même. Seule nous a inspiré notre piété pour le chef-d’œuvre. Nous ne souhaitons pas faire servir nos tréteaux a un spectacle bien fait et adroitement adapté au goût du public, mais les ennoblir, leur donner une âme, l'âme embrassée et pathétique de Féodor Mikhaïlovitch. Смысл театрального сотворчества с гением Достоевского был в том, чтобы облагородить зрителя, раскрыть ему «патетическую душу Феодора Михайловича». Этому манифесту был верен Гастон Бати, были верны все, кто творили 
спектакль, но, что удивительнее, ему стремились следовать режиссёры, которые обращались к версии Бати позже, десятилетия спустя, обращаются и наши современники.

\section{Литература}

- Baty, G. (1933) Crime et chatiment: 20 tableaux: Adaptés et mis en scène d’après F.M. Dostoiewsky, [Paris], (La Petite illustration. Théâtre; № 640 № 331).

- Baty, G. (1920) «Le Drame prétend réformé» Les Lettres, 1 novembre.

- Baty, G. (1926) Le masque et l'encensoir: Introd. à une esthétique du théâtre / Gaston Baty; Préf. de Maurice Brillant, Paris: Libr. Bloud \& Gay, 1926.

- Baty, G. (1919) «Les Cathédrales Dramatiques» Les Lettres, 1 juin et 1 juillet.

- Baty, G. (1949) Rideau baissé, [Paris]: Bordas.

- Baty, G. (1921) Sire le Mot // Les Lettres. 1921. 1 novembre.

- Blanchart, P. (1939) Gaston Baty: [L'homme et son œuvre], Paris: Éd. de la "Nouvelle revue critique".

- Borgal, C. (1963) Metteurs en scène: Jacques Copeau, Louis Jouvet, Charles Dullin, Gaston Baty, Georges Pitoëff. Paris: Lanore.

- Cahiers Gaston Baty (1966), N4.

- Гительман, Л.И. (2012) “Гастон Бати”, Памяти Льва Иосифовича Гительмана, СПб.; СПБГАТИ, с. 34-63.

- Гительман, Л.И. (1988) Идейно-творческие поиски французской режиссуры XX века, Л.

- Гительман, Л. (1978) «Достоевский на сценах Парижа», Русская классика на французской сцене, Л.

- Hort Jean (1976) Les théâtres du Cartel et leurs animateurs: Pitoëff, Baty, Jouvet, Dullin, Paris: Éditions d'Aujourd'hui.

- Kemp R. (1956) La vie du théâtre, (Paris).

- Lemaître Jules (1888-1898) Impressions de théâtre. 4e sér. C.247-260. https://gallica.bnf.fr/ark:/12148/bpt6k204340s/f263.image.r=Impressions\%20de\%20th\%C3\%A9\%C3\%A2tre

- Орлова, Н. Х. (2017) «Достоевскй во француском кино: к началу традиции» ПРАЕНМА, 4 (14), стр. 90-104.

- Финкельштейн, Е. Л. (1974) Картель четырех. Французская театральная режиссура между двумя войнами. Шарль Дюллен, Луи Жуве, Гастон Бати, Жорж Питоев, Л.: Искусство, Ленингр. отд-ние. 
Nadezhda Kh. Orlova Theology Department Yaroslav-the-Wise Novgorod State University (Veliky Novgorod - St.Petersburg, Russia)

\title{
"CRIME AND PUNISHMENT" BY FYODORDOSTOEVSKY ACCORDING TO GASTON BATY
}

\begin{abstract}
The article concerns theatrical adaptation of Fyodor Dostoevsky's novel Crime and Punishment. The play was first offered to the public by director Gaston Baty in 1933 on the stage of the Montparnasse Theatre. The production was a great success and entered the golden reserve of the history of French theatre. For many years, Crime and Punishment, according to the version proposed by Gaston Baty, has been played on the stages of French theatres. The article introduces a new archival document into circulation.
\end{abstract}

Keywords

Fyodor Dostoevsky, Crime and Punishment, Gaston Baty, French theater, theatrical adaptations, Cartel of four

Primljeno: 14.8.2021.

Prihvaćeno: 4.9.2021. 